\title{
O PAPEL DA MARCA NO CONSUMO DE ALIMENTOS
}

Dario de Oliveira LIMA-FILHO ${ }^{1}$

Filipe QUEVEDO-SILVA

Bruno GUBIOTTI ${ }^{3}$

Pedro Augusto MACHADO ${ }^{4}$

Uriel RAGHIANT FILHO 5

\begin{abstract}
${ }^{1}$ Doutor em Administração pela FGV. Professor do Programa de Pós-Graduação em Administração da Universidade Federal de Mato Grosso do Sul. dariolimafilho@gmail.com

${ }^{2}$ Doutor em Administração pela Universidade Nove de Julho. Professor do Programa de Pós-Graduação em Administração da Universidade Nove de Julho. filquevedo@gmail.com

${ }^{3}$ Bacharel em Administração pela Universidade Federal de Mato Grosso do Sul. bruno_10gubiotti@hotmail.com

${ }^{4}$ Bacharel em Administração pela Universidade Federal de Mato Grosso do Sul. pedroaugusto_machado@hotmai.com

${ }^{5}$ Mestre em Administração pela Universidade Federal de Mato Grosso do Sul. uriel.raghiant@gmail.com
\end{abstract}

Recebido em: 12/02/2016 - Aprovado em: 09/08/2016 - Disponibilizado em: 18/12/2016

\begin{abstract}
RESUMO
O objetivo deste trabalho foi avaliar o papel da marca no consumo de alimentos. Em termos específicos, pretende-se verificar a influência da marca na escolha dos alimentos e identificar os fatores que são mais relacionados à marca pelos consumidores. Para tanto, foi realizado um estudo quantitativo descritivo junto a 110 consumidores maiores de 18 anos, de ambos os sexos e de todas as classes econômicas, que realizam compras em supermercados. Os dados foram coletados em junho de 2012. As variáveis de análise foram: benefícios prometidos pela marca, confiança, preço, status, responsabilidade social, saúde e qualidade. A marca exerce influência na escolha de alimentos para todos os entrevistados, sendo que para a maioria essa influência é grande. O status foi a variável de menor peso para os entrevistados, seguida da responsabilidade social, benefícios prometidos e preço. As de maior peso foram a confiança, saúde e qualidade. Os resultados apontam ainda uma relação significativa entre o peso atribuído à marca e os atributos preço e confiança.
\end{abstract}

Palavras-chave: Alimentação; Comportamento do consumidor; Varejo.

\begin{abstract}
The purpose of this paper was to evaluate the role of the brand in food consumption. Specifically, we intend to check the brand influence in food choice and identify the factors that are most related to the brand by consumers. To that end, we conducted a descriptive quantitative study with 110 consumers aged 18 years or more, of both sexes and of all economic classes, which was shopping in supermarkets. Data were collected in June 2012. The variables analyzed were: benefits promised by brand, trust, price, status, social responsibility, health and quality. The brand influences the choice of food for all respondents, and for most them this influence is great. The variable status had the lowest weight for the respondents, followed by social responsibility, promised benefits and price. The ones with the greatest weight were trust, health and quality. The results also indicate a significant relationship between the weight given to brand and the attributes price and trust.
\end{abstract}

Keywords: Alimentation, Consumer Behavior, Retail. 


\section{INTRODUÇÃ̃O}

A apresentação visual dos alimentos fornece considerável informação e pode afetar o comportamento do consumidor. Sabe-se que um produto alimentício bem apresentado, com o uso adequado de embalagem, cores, informações nutricionais e posicionamento correto no estabelecimento comercial, tende a influenciar fortemente a decisão de compra.

A história da alimentação e o homem estão juntos desde a concepção da vida, pois todas as pessoas precisam de alimentação para sua existência, pelo caráter essencial que esse encontra naquela em seu dia-a-dia (ALBERTS, 1997).O homem precisa, para sua sobrevivência, de múltiplos substratos energéticos, entre os quais: hidratos de carbono, proteínas e lipídios, naturais nos alimentos (GUEDES; GUEDES, 2003).

Para Krause (2002) a preocupação com a boa alimentação vem ganhando força nos últimos anos, com o surgimento da geração das pessoas que buscam alimentos que tragam benefícios à saúde. A evolução dos hábitos alimentares acontece de forma bastante lenta e de acordo com as necessidades do homem (FLANDRIN e MONTANARI, 1998).Os consumidores possuem hábitos alimentares específicos e de acordo com a oferta dos produtos fazem sua escolha de compra.A modificação de hábitos alimentares, com o objetivo de buscar uma melhor qualidade de vida, é cada vez mais trabalhosa, pois cada nação, povo, cultura e região geográfica possui aspectos sociais e econômicos que definem os seus padrões alimentares (FLANDRIN e MONTANARI, 1998).

Os consumidores tendem a escolher o produto que melhor supre suas necessidades alimentares, porém a escolha por um produto diferenciado, apenas pela marca, pode trazer maus hábitos alimentares, em termos nutricionais. A oferta dos produtos, acompanhada do consumo excessivo de alimentos nem sempre é sinônimo de qualidade de vida, pois um grande consumo de alimentos pode provocar doenças, como a obesidade (KRAUSE, 2002).

A obesidade pode ser considerada um distúrbio metabólico, muito comum no homem moderno e causa danos à saúde das pessoas. Sua gênese é decorrente de uma série de fatores de natureza genética, ambiental e social, que é desencadeada pelo balanço energético positivo, quando a ingestão alimentar é maior que o gasto energético (GUEDES; GUEDES, 2003). Este mesmo autor associa a origem da obesidade humana como fortemente influenciada por condições e hábitos alimentares. Para Nóbrega (1998), além dos fatores de risco, genético e alimentar, o estilo de vida da família está relacionado ao gasto energético.

$\mathrm{O}$ excesso de nutrientes em conjunto com erros no metabolismo normal torna-se um risco em potencial para desencadear 
doenças associadas à obesidade, como: diabetes; hipertensão; dislipidemias; entre outras (KRAUSE, 2002). Hoje em dia, a quantidade de obesos e pessoas com sobrepeso demonstra a dificuldade que o consumidor tem de controlar seu peso e de escolher o produto mais adequado para uma alimentação saudável, pois além dos clientes possuírem motivações para o consumo excessivo de produtos, existem muitos produtos ofertados e a escolha se torna complicada, nem sempre sendo realizada da maneira mais adequada. Um dos fatores que podem ser levados em conta na escolha do produto é a marca.

Para Krause (2002), a tendência atual é de pessoas que escolham seus produtos de acordo com informações nutricionais do alimento, buscando uma alimentação saudável e a marca do produto pode ser um diferencial na hora da escolha. Existe a dificuldade na seleção do produto a ser consumido e os consumidores buscam por diferenças que os ajudem a escolher aquele que é o mais adequado.

$\mathrm{Na}$ escolha do produto, o cliente procura aquele que traz maiores benefícios em relação aos custos. Para Kotler (2000), o valor percebido pelo consumidor de um produto é calculado pela diferença dos custos inerentes ao produto e os benefícios que eles trazem ao cliente. Na escolha do produto, o cliente pode optar pelo de menor preço, por um de boa qualidade, por aquele que oferece soluções customizadas, por um novo produto e até por um que possua uma marca forte no mercado. É importante compreender o conceito de valor percebido pelo cliente para entender a escolha do produto. Assim, é necessário conhecer a percepção que o consumidor tem de determinado produto, para saber se um produto específico alinha-se a um determinado tipo de consumidor.

A imagem e a marca do produto estão alinhadas na escolha e satisfação do cliente. Com um marca forte os clientes tendem a comprar mais, porém é importante analisar os benefícios à saúde que os produtos trazem aos seus consumidores quando o assunto é alimentos, e por isso, esse trabalho procura identificar como a marca do produto influencia no consumo dos clientes.

Portanto, o objetivo geral deste estudo é avaliar o papel da marca no consumo de alimentos. Em termos específicos, pretende-se verificar a influência da marca na escolha dos alimentose identificar os fatores que são mais relacionados à marca pelos consumidores.

\section{REFERENCIAL TEÓRICO}

De acordo com Guedes e Guedes (2003, p.155) é imprescindível distinguir dois conceitos inclusos nos hábitos alimentares das pessoas: alimentação e nutrição. Para os autores acima "a alimentação é um processo que se identifica com a seleção e a ingestão de produtos que, de acordo com a 
disponibilidade e as preferências de paladar, procuram atender às necessidades orgânicas manifestadas pela fome”, enquanto a nutrição, por sua vez, é um "conceito amplo e complexo", que confere com uma dieta em que os alimentos, que possuem os nutrientes exatos e correlatos de acordo com a necessidade de cada pessoa, são ingeridos nas quantidades apropriadas e com a classificação necessária de nutrientes para manter a saúde equilibrada, atualmente e no futuro.

É importante destacar que hábitos nutricionais e alimentares não são expressões análogas, que podem ser empregadas indistintamente. A alimentação estabelece processos em que predomina o desejo de satisfação sobre o de necessidade, porém o conceito de nutrição está implicitamente conexo com a realização de uma dieta adequada, de acordo com os nutrientes presentes nos alimentos.

Para Krause (2002), nutrição pode ser definida como a combinação de processos através dos quais o organismo vivo recebe e utiliza os materiais [alimentos] necessários à manutenção de suas funções e ao crescimento e renovação dos seus constituintes. Justamente pela existência e essencialidade de seus nutrientes, os alimentos são indispensáveis para a vida e desenvolvimento das pessoas (ALBERTS, 1997). De acordo com a OMS apud WHO (2003, p. 08) "nutrição é a ingestão de alimentos, tendo em conta as necessidades alimentares do corpo".
De acordo com Guedes e Guedes (2003) analisar os hábitos alimentares das pessoas permite fazer implicações de como conseguir objetivos nutricionais e sobre perda, conservação ou ganho de massa corporal, visando a busca de uma vida saudável. Segundo os mesmos autores, para conseguir o objetivo de uma vida saudável, as pessoas precisam alterar os hábitos alimentares, para uma dieta adequada e equilibrada, acordada com atividade física regular. Para a OMS apud WHO (2003, p.10)a consequência do não comprometimento com hábitos alimentares adequados e atividades físicas regulares, as pessoas podem sofrer com doenças originárias de uma alimentação inadequada, podendo levar à "redução da imunidade, aumento da suscetibilidade a doenças, prejudicando o desenvolvimento físico e mental".

Para Alberts (1997) e Krause (2002), os hábitos alimentares, adequados ou não, são formados no período da infância das pessoas, e podem ser os mesmos por toda a vida, se não houver preocupação em alterá-los. Segundo Krause (2002) e Nóbrega (1998), os nutrientes e a energia da dieta devem ser suficientes para assegurar o desenvolvimento e evitar que a proteína de reserva seja empregada para energia, mas sua ingestão não deve ser exagerada, de maneira que não resulte em obesidade. A proporção sugerida é de 50 a $60 \%$ de carboidratos, 25 a $35 \%$ como 
gorduras, e de 10 a 15\%, como proteínas, em relação às calorias totais (KRAUSE, 2002).

O mesmo autor acima afirma que as doenças causadas pela falta de nutrientes essenciais ao organismo referem-se a um conjunto de distúrbios clínicos que têm como causa a deficiência de proteínas e de energia na alimentação, e se manifesta principalmente na infância. Já para Nóbrega (1998), o baixo consumo de minerais e vitaminas intervém de forma acentuada na saúde das pessoas, principalmente das crianças. "Os principais problemas envolvendo a nutrição e a alimentação decorrem do consumo excessivo ou da carência de determinados nutrientes" (KRAUSE, 2002).

A definição de alimentação saudável é estabelecida de acordo com determinados elementos, como "experiências de vida, fontes de informação, mudanças nas regras sociais, prioridades e restrições, assim como também algumas características sociais e demográficas" (FALK et al., 2001). Para este mesmo autor, o conceito de alimentação saudável pode ser modificado ao longo da vida, variando em complexidade e contexto.

De acordo com a OMS apud WHO (2003), a alimentação saudável é um exercício difundido em três conceitos importantes: "a variedade de alimentos como fonte de nutrientes, o equilíbrio energético baseado nas necessidades individuais e a moderação pelo controle do consumo de alimentos energéticos, procedentes de gorduras e açúcares simples". De acordo com Silvia (2011), a alimentação saudável é definida como:

Ela é composta por três tipos de alimentos: com alta concentração de carboidratos, como: grãos, pães, massas tubérculos e raízes; frutas e hortaliças; alimentos vegetais, como: cereais integrais, leguminosas, sementes e castanhas; alimentos de origem animal, como: carnes, leite e derivados com baixos teores de gorduras. Frente à associação do consumo elevado de determinados compostos nutricionais e doenças crônicas não transmissíveis, algumas orientações com caráter restritivo são também enfatizadas como: reduzir o consumo de gorduras totais, gorduras saturadas, gorduras vegetais hidrogenadas, açúcar e sódio.

Com relação ao marketing de incentivo à alimentação e vida saudáveis, os alimentos que usam a propaganda, em sua maioria, fazem parte do grupo da pirâmide que devem ser consumidos em porções moderadas e uma minoria dos alimentos que fazem parte dos níveis da pirâmide composta por frutas e vegetais. Observa-se, em estudos, que grande parte das propagandas de alimentos não traz adequações às recomendações de alimentação saudável, o que leva a problemas de saúde, em caso de consumo excessivo.

Para Silvia (2011, p.7), “as práticas de marketing vinculam a alimentação saudável ao consumo de alimentos industrializados e não privilegiam os alimentos naturais e menos 
refinados, os quais são de produção factível em várias regiões brasileiras, principalmente por pequenos agricultores familiares". Há que se levar em conta, também, o fato de que os alimentos que não são saudáveis são os mais acessíveis e com maior disponibilidade para a população.

Segundo Falk et al (2001), “além de serem disseminadas por guias alimentares e mídia, as informações sobre alimentação saudável também são divulgadas por profissionais de saúde e canais informais, como diálogo com amigos e família”. A abundância de canais de informação pode induzir a contradições e conceitos impróprios sobre o tema e impedir a adoção de hábitos alimentares verdadeiramente saudáveis. Nesse processo, onde existem vários canais de informação, a marca se destaca na etapa de decisão de compra, pois é um dos mais explorados meios de marketing para convencimento, no momento da compra.

Para Kotler (2000, p.426), uma marca "demonstra a empresa ou o fabricante" e "pode ser um nome, uma marca comercial, um logotipo ou outro símbolo". Uma marca é essencialmente uma promessa da empresa de fornecer uma série específica de atributos, benefícios e serviços uniformes aos compradores. As melhores marcas trazem uma garantia de qualidade. "De acordo com a lei das marcas comerciais, a empresa adquire direitos exclusivos e vitalícios sobre o uso do nome da marca. As marcas diferem de outras propriedades como patentes e direitos autorais, que possuem datas de expiração" (KOTLER, 2000).

De acordo com Martins (2006), marca é a união de atributos tangíveis e intangíveis, simbolizados num logotipo, gerenciados de forma adequada e que criam influência e geram valor. Trata-se de um sistema integrado que promete e entrega soluções desejadas pelas pessoas.

Nessa mesma linha de pensamento, Kotler (2000) afirmam que a marca pode envolver atributos, como "bem durável", de "alto prestígio" e de "alto preço"; benefícios, uma vez que os consumidores compram benefícios, tanto funcionais como emocionais; valores para o consumidor, como segurança e prestígio; e personalidade, projetada a partir da personalidade que o comprador tem ou gostaria de ter no objeto.

Uma marca é essencialmente uma promessa da empresa de fornecer uma série específica de atributos, benefícios e serviços uniformes aos compradores. As melhores marcas trazem uma garantia de qualidade (KOTLER, 2000). Para Kotler (2000, p.194) "quando uma pessoa avalia marcas, ela reage não apenas às possibilidades declaradas das marcas, mas também a outros sinais menos conscientes. A forma, o tamanho, o peso, o material, a cor e o nome da marca podem estimular certas associações e emoções".

A importância do marketing para as empresas, no intuito de formar uma marca 
forte no mercado, pode conter ações de marketing na Internet, em revistas, em jornais, no ponto de venda, junto ao pós-venda, gerando mais valor para os consumidores, ou então, caso contrário, os consumidores vão em busca de produtos similares na concorrência. $\mathrm{O}$ consumidor procura no mercado um produto que seja confiável, de uma marca conhecida e que possua um marketing planejado às suas necessidades.

Kotler (2000) afirma que uma marca é um símbolo complexo, podendo trazer até seis níveis de significado:

a) Atributos: uma marca traz à mente certos atributos;

b) Benefícios: os atributos devem ser traduzidos em benefícios funcionais e emocionais;

c) Valores: a marca também diz algo sobre os valores da empresa;

d) Cultura: a marca pode representar certa cultura;

e) Personalidade: a marca pode projetar certa personalidade;

f) Usuário: a marca sugere o tipo de consumidor que compra ou usa o produto.

De acordo com um estudo realizado recentemente pela FIESP - Federação das Indústrias do Estado de São Paulo -, o brasileiro está se alinhando às tendências mundiais no setor de alimentos e bebidas. Tal estudo apontou que o conhecimento do produto e a marca são os aspectos mais importantes no momento da compra. Outro ponto a ser considerado é o fator qualidade do produto a ser adquirido. Esta, segundo o estudo, é o fator que mais provoca admiração e respeito dos consumidores.

Para Kotler (2000), uma boa estratégia de marketing para o posicionamento de marca deve estar pautada em três pontos principais: segmentação, mercado-alvo e posicionamento. A empresa, combinando esses fatores, consegue descobrir as necessidades, os diversos grupos de consumidores no mercado, estabelecendo um público-alvo para apresentar produtos ou serviços com preços mais baixos que os demais concorrentes. Outra estratégia utilizada pelas empresas é a diferenciação baseada no produto, na qual as marcas podem contribuir para o produto ou serviço, passando uma mensagem de qualidade superior, que é traduzida no aumento das vendas, no retorno sobre investimento, permitindo cobrar um preço superior. Assim, o cliente passa a fazer compras repetidas, tornando-se fiel à marca.

Ainda segundo o autor, a marca deve adicionar valor aos produtos e serviços, sendo que esse valor a mais deve refletir no modo como os consumidores pensam, interagem e sentem ao consumir o produto. Surge, então, o conceito de Branding, que pode ser entendido como uma abordagem de gestão com a finalidade de aumentar a atratividade da marca. O Branding também está relacionado à criação de novos mercados, pois é utilizado 
quando uma nova categoria é criada. Segundo Sampaio (2002), Branding é um conjunto de tarefas de marketing e de comunicação destinadas a otimizar a gestão das marcas. A marca, para ser influenciadora, precisa estar na mente do consumidor e nas experiências vivenciadas por ele. Esse processo poder ser definido como Brand Equity.

O Brand Equity utiliza-se de vários modelos e diretrizes para saber se uma marca tem impacto sobre a preferência do consumidor na hora da compra, como a diferenciação, que mede o grau no qual a marca é vista como diferente das outras, a relevância, que mede a amplitude do apelo à marca, estima, que mede como a marca é conceituada e respeitada, e por último o conhecimento, que mede o quanto os clientes se sentem familiarizados e confortáveis com a marca.

\section{METODOLOGIA}

A metodologia do trabalho foi de pesquisa de campo, descritiva, experimental com análise de dados quantitativa (MALHOTRA, 2006). A população-alvo da pesquisa foi composta por consumidores de produtos alimentícios, moradores da zona urbana do Município de Campo Grande, Estado de Mato Grosso do Sul, com 18 anos ou mais, pertencentes às classes A, B, C, D e E, responsáveis pela compra de alimentos para sua família. Foram realizadas 110 entrevistas em junho de 2012.

Para o cálculo do tamanho da amostra, considerou-se uma população infinita. Utilizando um intervalo de confiança [IC] de 95\% e erro padrão [EP] de $10 \%$, com base na fórmula para o cálculo do tamanho da amostra aleatória simples para descrição da proporção populacional (BUSSAB; MORETTIN, 2011), chegou-se a uma amostra de 97 indivíduos. Contudo, para maior segurança, aplicou-se 110 questionários, fazendo com que o EP fosse reduzido para aproximadamente $9,4 \%$ (AAKER; KUMAR; DAY, 2001).

Para analisar os efeitos da marca sobre os hábitos alimentares, este estudo abordou: a) Os hábitos alimentares dos respondentes, baseado nas recomendações do Ministério da Saúde; b) A influência da marca, abrangendo as preferências do consumidor referentes a diferenciação, relevância, estima e conhecimento; c) Variáveis sóciodemográficas, englobando sexo, idade, escolaridade e renda.

A coleta de dados foi realizada com a adoção de entrevistas face-a-face [interrogatório direto], com abordagem na porta de três supermercados de diferentes regiões da cidade, utilizando-se um questionário estruturado. A análise dos dados foi realizada por meio de estatística descritiva, por meio de distribuição de frequência e medidas de tendência, com o auxílio do 
software Minitab (MINITAB, 2010), além de análise de correlação e regressão linear.

\section{RESULTADOS E DISCUSSÃO}

Conforme os dados da Tabela 1, percebe-se que similaridade diante do sexo dos entrevistados no supermercado, sendo homens [47\%] e mulheres [53\%]. A escolaridade dos entrevistados demonstra que $57 \%$ possui no mínimo ensino médio completo, sendo $37 \%$ cursando ou com ensino superior completo e 5\% com pós-graduação. A distribuição da renda familiar demonstra que a maior parcela enquadra-se entre 4 e 6 salários, mas muitos estão acima desse padrão de renda.

Tabela 1. Perfil dos entrevistados:

\begin{tabular}{|l|c|c|}
\hline \multicolumn{1}{|c|}{ Variáveis } & N & \% \\
\hline Gênero: & 52 & $47,27 \%$ \\
\hline Masculino & 58 & $52,73 \%$ \\
Feminino & \multicolumn{2}{|c|}{} \\
\hline Escolaridade: & 3 & $2,73 \%$ \\
\hline Primário & 11 & $10,00 \%$ \\
Fundamental & 49 & $44,55 \%$ \\
Médio & 41 & $37,27 \%$ \\
Superior & 6 & $5,45 \%$ \\
Pós-graduação & \multicolumn{2}{|c|}{} \\
\hline Renda Familiar Mensal: & 19 & $17,27 \%$ \\
\hline 1 a 3 salários & 37 & $33,64 \%$ \\
4 a 6 salários & 24 & $21,82 \%$ \\
7 a 9 salários & 30 & $27,27 \%$ \\
10 ou mais salários & \multicolumn{3}{|c|}{} & \\
\hline
\end{tabular}

Fonte: elaborado pelos autores

para compreender como os clientes percebem

Dentre os atributos utilizados como variáveis na percepção de marca estão: benefícios prometidos pela marca, confiança, preço, status, responsabilidade social, saúde e qualidade. Essas variáveis foram utilizadas os atributos da marca em relação ao produto.

A Tabela 2 demonstra os dados da análise e a importância desses atributos.

Tabela 2. Principais atributos da marca percebidos pelos clientes:

\begin{tabular}{|l|c|c|c|c|c|}
\hline Variável & $\begin{array}{c}\text { Não } \\
\text { Influencia }\end{array}$ & $\begin{array}{c}\text { Influencia } \\
\text { Pouco }\end{array}$ & Indiferente & Influencia & $\begin{array}{c}\text { Influencia } \\
\text { Muito }\end{array}$ \\
\hline Confiança & $0,0 \%$ & $20,0 \%$ & $30,0 \%$ & $43,6 \%$ & $6,4 \%$ \\
\hline Preço & $5,5 \%$ & $4,6 \%$ & $28,2 \%$ & $24,6 \%$ & $37,3 \%$ \\
\hline Benefícios & $7,3 \%$ & $10,9 \%$ & $26,4 \%$ & $24,6 \%$ & $30,9 \%$ \\
\hline Status & $30,0 \%$ & $26,4 \%$ & $32,7 \%$ & $8,2 \%$ & $2,7 \%$ \\
\hline $\begin{array}{l}\text { Responsabilidade } \\
\text { Social }\end{array}$ & $16,4 \%$ & $17,3 \%$ & $28,2 \%$ & $18,2 \%$ & $20,0 \%$ \\
\hline Saúde & $6,4 \%$ & $2,7 \%$ & $14,6 \%$ & $27,3 \%$ & $49,1 \%$ \\
\hline Qualidade & $4,6 \%$ & $2,7 \%$ & $6,4 \%$ & $30,9 \%$ & $55,5 \%$ \\
\hline
\end{tabular}

Fonte: realizado pelos autores 
O status foi a variável de menor peso para os entrevistados, com uma nota média de 2,2. Depois dela vem a responsabilidade social com 3,0. Em seguida vem as variáveis benefícios prometidos e preço. As de maior peso foram a confiança, saúde e qualidade.

Para Kolter (2000) confiança é importante para formar um marketing de relacionamento forte e construir uma relação duradoura com o cliente. $\mathrm{O}$ atributo confiança com $50 \%$ tem um peso considerável na hora da compra pelos consumidores que o colocam como importante variável, pois os clientes sabem que na aquisição do produto/alimento tem todos os benefícios prometidos, essa relação entre confiança e marca do produto é estabelecida com o tempo, no qual os consumidores têm suas experiências do consumo e estabelecem opiniões sobre o produto.

O preço é, provavelmente, o mais naturalmente comparado pelo consumidor no momento da compra. Os atributos como qualidade e benéficos, são percebidos após o momento da compra ou são motivos de influência de outros consumidores e podem ser percebidos após a compra. Para as empresas o preço tem que ser determinado com exatidão. Para determinar o preço, as empresas têm de analisar basicamente os objetivos de venda e lucros, os custos de produção, a demanda e suas características e a concorrência no mercado. Segundo o quadro demonstra que $61 \%$ dos consumidores acham importantes os valores do produto/alimento, e suas compras são baseadas exclusivamente no preço. Os benefícios decorrentes da marca são visualizados como importantes na hora da compra por $51 \%$ da amostra.

Variáveis como status e responsabilidade social, respectivamente com $56 \%$ e $34 \%$, demonstram que em nível de importância na hora da compra do produto/alimento pelos consumidores, se mostram indiferentes em relação a estes atributos ou não dão muita importância. $\mathrm{O}$ status é um importante atributo de percepção de valor para produtos que possuem alto valor agregado, como os alimentos são produtos mais comuns e normalmente não possuem alto valor agregado esse atributo não é muito visualizado. A responsabilidade social demonstra que a marca pode representar uma ideia de obrigação legal e ainda um comportamento ético com a sociedade. Muitas pessoas a equiparam a uma contribuição caridosa, ou ao sentido de ser socialmente consciente. Uns poucos a veem apenas como uma espécie de dever das empresas.

O atributo saúde [76\%] é considerado como de muita importância na escolha do produto/ alimento pelo consumidor. Para Krause (2002) os consumidores revelam ser de muita importância à saúde na visualização dos alimentos, pois existe uma tendência desde os anos 90 de se alimentar melhor, com padrões específicos de nutrição para cada 
idade. Krause (2002) comenta também que esses fatores dependem da etnia, cultura, capacidade financeira e ambiente de vida, pois ainda existem pessoas que preferem arriscar com alimentos não saudáveis. Parar os entrevistados a importância da saúde nos produtos/alimentos é de mais de $70 \%$, demonstrando a importância desse atributo para os consumidores.

Para Kotler (2000, p.48) “os clientes estão exigindo mais qualidade e serviço superiores, além de alguma customização. Eles percebem menos diferenças reais entre produtos e mostram menos fidelidade a marcas". Para $86 \%$ dos entrevistados a qualidade é o atributo da marca que mais importa na hora da compra, fato que torna esse atributo, junto com saúde como o mais importante na visualização da marca. Para Kotler (2000) as melhores marcas trazem uma garantia de qualidade.
$\mathrm{Na}$ análise da importância da marca pelos clientes, nenhum dos entrevistados respondeu que a marca não influencia na hora da compra, o que demonstra que todos os entrevistados acreditam que a marca possui relevância na decisão de compra. Entre os entrevistados $70 \%$ acham a marca importante ou muito importante na escolha dos alimentos.

Em relação à importância atribuída à marca no momento da compra, foi possível perceber uma relação entre esse comportamento e o peso dado a alguns atributos de compra.A tabela 3 apresenta as médias e desvios padrões bem como a matriz de correlação entre as variáveis da pesquisa com seus respectivos níveis de significância. Para a análise de correlação foram considerados os níveis de $1 \%$ e $5 \%$.

Tabela 3: Matriz de correlação

\begin{tabular}{|c|c|c|c|c|c|c|c|c|c|c|}
\hline & Média & $\begin{array}{l}\text { Desvio } \\
\text { Padrão }\end{array}$ & 1 & 2 & 3 & 4 & 5 & 6 & 7 & 8 \\
\hline 1. Importância da Marca & 3,95 & 0,83 & 1 & & & & & & & \\
\hline 2. Confiança & 4,1 & 0,94 & $296^{* * *}$ & 1 & & & & & & \\
\hline 3. Preço & 3,83 & 1,14 &,$- 199^{*}$ &,- 026 & 1 & & & & & \\
\hline 4. Benefícios Prometidos & 3,6 & 1,23 &, 018 & ,092 & ,084 & 1 & & & & \\
\hline 5. Status & 2,72 & 1,06 &, 045 &,- 057 &,- 008 & ,103 & 1 & & & \\
\hline 6. Responsabilidade Social & 3,08 & 1,34 &, 052 &, $217^{*}$ &,- 033 &, 102 &, $220^{*}$ & 1 & & \\
\hline 7. Saúde & 4,1 & 1,14 &,- 100 & ,066 &, $215^{*}$ &, $416^{* *}$ & ,097 &, $261^{* *}$ & 1 & \\
\hline 8. Qualidade & 4,3 & 1,03 &,- 015 &, $237^{*}$ &, 182 &, $260^{* *}$ &, $238^{*}$ &, $257^{* *}$ & $466^{* *}$ & 1 \\
\hline
\end{tabular}

Fonte: Elaborado pelos autores

A Tabela 4apresenta o resultado do modelo de regressão. Assim como pode ser observado, apenas duas variáveis apresentaram relação significativa com a importância atribuída a marca pelos consumidores no momento da compra. A confiança apresentou relação positive, indicando o papel diagnóstico que a marca exerce sobre os consumidores. Ao conhecer e 
Tabela 4: Regressão

\begin{tabular}{|l|c|c|c|l|r|}
\hline Variável & Beta & T & Sig. & F & 7,602 \\
\hline Confiança & $0,292^{*}$ & 3,222 &, 000 & R2 & 0,12 \\
\hline Preço & $-0,191 *$ & $-2,112$ &, 037 & R2 ajustado & 0,11 \\
\hline Benefícios Prometidos & 0,045 &, 443 &, 659 & & \\
\cline { 1 - 3 } & 0,076 &, 802 &, 424 & & \\
\cline { 1 - 3 } Status & $-0,089$ &,- 797 &, 427 & & \\
\cline { 1 - 3 } Qualidade & $-0,047$ &,- 425 &, 672 & & \\
\cline { 1 - 3 }
\end{tabular}

Fonte: Elaborado pelos autores

Já a variável preço apresentou relação negative, indicando que quanto menos peso os consumidores dão ao preço dos produtos, mais dispostos estão a comprar suas marcas de preferência.

Consideravelmente as marcas influenciam nas opções de escolha de produtos/alimentos em detrimentos a outros mesmos não tendo muitas diferenças de características físicas, mesmo que os consumidores não tenham conhecimentos sobre os benefícios, qualidades e saúdes. Geralmente são influenciados pelo senso comum ou experiências cognitivas próprias que envolvem raciocínio, percepção, memória, linguagem e psicologia. Fato que comprova que da amostra de 110 candidatos $82 \%$ dos consumidores relatam que compram produtos pela marca mesmo não conhecendo e apenas $18 \%$ procuram adquirir informações do produto/alimentos antes de consumir mesmo já conhecendo a marca.

demonstra que todos os entrevistados acreditam que a marca possui relevância na decisão de compra. Entre os entrevistados

\section{CONSIDERAÇÕES FINAIS}

Este trabalho teve como objetivo avaliar o papel da marca no consumo de alimentos. Em termos específicos, pretende-se verificar a influência da marca na escolha dos alimentos e identificar os fatores que são mais relacionados à marca pelos consumidores. Para tanto, foi realizado um estudo quantitativo descritivo junto a 110 consumidores maiores de 18 anos, de ambos os sexos e de todas as classes econômicas, que realizam compras em supermercados.

O status foi a variável de menor peso para os entrevistados, seguida da responsabilidade social, benefícios prometidos e preço. As de maior peso foram a confiança, saúde e qualidade. $\mathrm{Na}$ análise da importância da marca pelos clientes, nenhum dos entrevistados respondeu que a marca não influencia na hora da compra, o que $70 \%$ acham a marca importante ou muito importante na escolha dos alimentos.

Os resultados apontam ainda uma relação significativa entre o peso atribuído à 
marca e alguns dos fatores analisados. Entre os entrevistados que atribuíram maior importância à marca, o atributo preço foi menos valorizado, demonstrando que esses, muitas vezes, estão dispostos a pagar mais caro para ter um produto de marca conhecida ou que possua outros atributos de interesse. Além disso, também houve notas maiores para o atributo confiança, ou seja, para estes, quando estão comprando uma marca conhecida entendem que podem confiar naquele produto, o que se torna importante, principalmente nas compras de produtos alimentícios.

As limitações da pesquisa referem-se à pequena amostra coletada que acaba aumentando o erro amostral e a impossibilidade de se realizar análises quantitativas mais robustas em função dos dados obtidos. Sugere-se a realizações de estudos semelhantes a este, com maiores amostras e em outras regiões do país, de modo a dar suporte aos resultados encontrados aqui, além da utilização de novas variáveis que possam a dar mais subsídios para as discussões.

O presente trabalho tem implicações gerenciais, principalmente para as empresas produtoras de alimentos. As características dos consumidores identificadas na pesquisa pode ajudá-las a direcionar os esforços e recursos para uma melhor comunicação e disseminação de suas marcas, tornando seus produtos mais conhecidos, de maior credibilidade e, por consequência, com maior probabilidade de serem escolhidos pelos consumidores.

\section{REFERÊNCIAS}

AAKER, D.; KUMAR, V.; DAY, G.

Pesquisa de Marketing. São Paulo: Editora Atlas, 2001.

\section{ALBERTS, B. Biologia molecular da célula.} Porto Alegre. Artesemedicas. 1997.

BUSSAB, W.O.; MORETTIN, P.A.

Estatística básica. 5 ed, São Paulo: Saraiva, 2006.

FALK L.W; SOBAL J; BISOGNI C.A; CONNORS M. Managing healthy eating: definitions, classifications, and strategies. Health Education Behavior: 2001.

FLANDRIN, J. L.; MONTANARI, M.História da Alimentação, tradução de Luciano Vieira Machado e Guilherme J. F. Teixeira. São Paulo: Estação Liberdade, 1998.

GUEDES, D.P; GUEDES, J.E.R.P. Controle de peso corporal: Composição corporal, Atividade física e Nutrição. 2 ed. Rio de Janeiro: Shape, 2003.

KOTLER, P. Administração de Marketing: a edição do novo milênio. São Paulo:

Prentice Hall, 2000.

KRAUSE. Alimentos, nutrição \&

dietoterapia. 5 ed. São Paulo: Roca. 2002.

\section{MALHOTRA, N. K. Pesquisa de}

Marketing: uma orientação aplicada. 4 ed. Porto Alegre: Bookman, 2006.

MARTINS, J. R. Branding, o manual para você criar, gerenciar e avaliar marcas. São Paulo: Global Brands, 2006.

MINITAB. Minitab statistical software user`s guide 2: data analysis and quality 
tools. Minitab Release 16. Minitab Inc., StateCollege, PA, USA, 2010.

NÓBREGA, F. J. Distúrbios da nutrição.

Rio de Janeiro: Revinter, 1998.

SAMPAIO, R. Marcas de A a Z: Como

construir e manter marcas e sucesso. Rio de Janeiro: Elsevier, 2002.

SILVIA, C. L. Consumo de frutas e hortaliças e conceito de alimentação saudável em adultos de Brasília. Brasília: 2011.

WHO - World Health Organization. Global strategy on diet, physical activity and health. Disponível em:

<http://www.who.int/gb/ebwha/pdf_files/WH A57/A57_R17-en.pdf >.Acesso em 05/05/2012. 